\title{
Financial Burden of Border Hospital in Caring for Cross-Border Patients: A Short Note From Thailand
}

\author{
Viroj Wiwanitkit ${ }^{1,2,3,4^{*}}$ \\ ${ }^{1}$ D. Y. Patil University, Pune, India \\ ${ }^{2}$ Faculty of Medicine, University of Nis, Serbia \\ ${ }^{3}$ Joseph Ayobabalola University, Ikeji-Arakeji, Nigeria \\ ${ }^{4}$ Chulalongkorn University, Bangkok, Thailand
}

*Corresponding Author: Viroj Wiwanitkit, Special Lecturer, Chulalongkorn University, Bangkok Thailand.

Tel: +66-24132436, Email: wviroj@yahoo.com

Received May 12, 2019; Accepted June 29, 2019; Online Published August 26, 2019

\section{Dear Editor,}

International border areas are usually remote. Cross border travel is not uncommon. There are a lot of formal and informal crossings ${ }^{1}$ and many aims of cross border travel. One is to seek medical care. Health control checkpoints play an important role in disease control. ${ }^{2}$ Each day, much cross-border travel around the world is performed by people seeking healthcare. According to basic humanistic welfare principles and human rights, it is the role of hospitals in border areas to provide necessary health services to cross-border patients seeking healthcare support. Because border areas are usually remote areas and the local people might be poor, the cost of healthcare services for cross-border patients is an interesting issue to be addressed. Here, the author would like to discuss the available data on the financial situation of border hospitals in border areas of Thailand, a tropical country in Indochina, in caring for cross-border patients.

The officially available primary data from the Thai Ministry of Public Health (available online at https://www. hfocus.org/content/2016/11/13425) are referred to in. ${ }^{3}$ The data collected from 54 border hospitals in 31 border provinces of Thailand in the year 2016 were analyzed. All hospitals are district hospitals, secondary level, located in border districts between Thailand and nearby countries (Myanmar, Cambodia, Lao PDR, and Malaysia). The nationalities of cross-border patients are Myanmar, Cambodian, Laotian, and Malaysian. The cross-border patients include both legal (migrant workers, refugees) and temporary (cross-border cases seeking urgent healthcare) patients. Cases managed by the hospitals include both acute and chronic illnesses with the main diseases being respiratory tract infections, diarrhea, and vector-borne diseases.
Of interest, all border hospitals reported a "loss of profit" financial status regarding providing healthcare for cross-border patients: The net loss of profit is equal to \$US12 966469.80, averaging \$US240119.80 per border hospital. Considering the neighboring countries, the loss of profit occurred at the most and least levels at the ThailandMyanmar border and the Thailand-Cambodia border, respectively. The hospitals with the highest burden due to cross-border patients are those located in the ThailandMyanmar border areas.

The setting for the present report is the well-known area for regional public health problems of cross-border patients. Due to long-term conflict in several Indochina countries, there are many cross-border travelers seeking a better life and peace. Many migrants and refugees exist in this area. ${ }^{4}$ Health equity becomes a big consideration in carrying those cross-border patients.., 5 Although an attempt has been made to establish regional universal health coverage within Indochina, ${ }^{5,6}$ there has been no success to date, and some countries have to carry the burden for the care of cross-border patients. Although basic health services for any patient, regardless of ethics or nationality, is the basic principle in medicine, there is an important medical economics consideration for border hospitals in caring for cross-border patients. Due to increased globalization in the present day, the management of cross-border patients becomes a very important issue in clinical travel medicine.

\section{Conflict of Interest Disclosures}

The authors declare that they have no conflicts of interest.

\section{Ethical Approval}

Not applicable.

Copyright $\odot 2019$ The Author(s). This is an open-access article distributed under the terms of the Creative Commons Attribution License (http:// creativecommons.org/licenses/by/4.0), which permits unrestricted use, distribution, and reproduction in any medium, provided the original work is properly cited. 


\section{References}

1. Wiwanitkit V. Informal International Border Crossing, Refugee and Illegal Migrant Workers: Issue in Travel Medicine. Int J Travel Med Glob Health. 2018;6(1):34. doi:10.15171/ ijtmgh.2018.07.

2. Wiwanitkit V. Border Disease Control Checkpoints: Are They Sufficient for Disease Control? The Present Situation in Thailand. Int J Travel Med Glob Health. 2019;7(1):38. doi:10.15171/ ijtmgh.2019.08.

3. Hfocus. https://www.hfocus.org/content/2016/11/13425.
Accessed June 25, 2019

4. McMichael C, Healy J. Health equity and migrants in the Greater Mekong Subregion. Glob Health Action. 2017;10(1):1271594. doi:10.1080/16549716.2017.1271594.

5. Guinto RL, Curran UZ, Suphanchaimat R, Pocock NS. Universal health coverage in 'One ASEAN': are migrants included? Glob Health Action. 2015;8:25749. doi:10.3402/gha.v8.25749.

6. Van Minh H, Pocock NS, Chaiyakunapruk N, et al. Progress toward universal health coverage in ASEAN. Glob Health Action. 2014;7:25856. doi:10.3402/gha.v7.25856. 